\title{
Gold-catalyzed naphthalene functionalization
}

\author{
Pedro J. Pérez*, M. Mar Díaz-Requejo* and Iván Rivilla
}

\section{Full Research Paper}

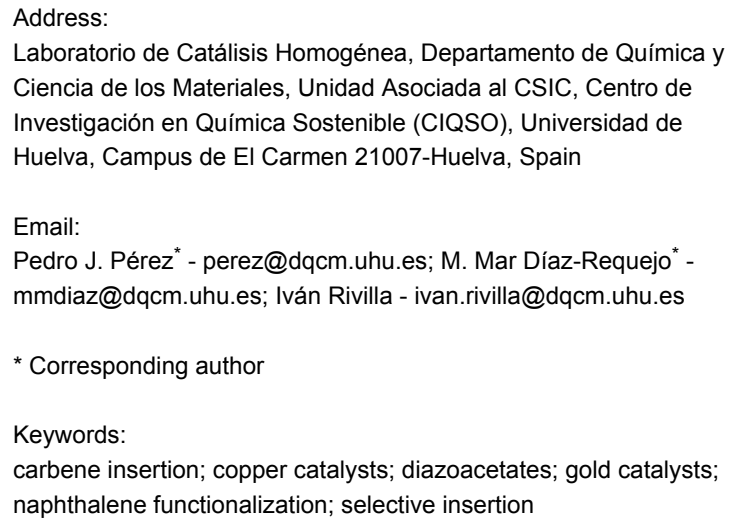

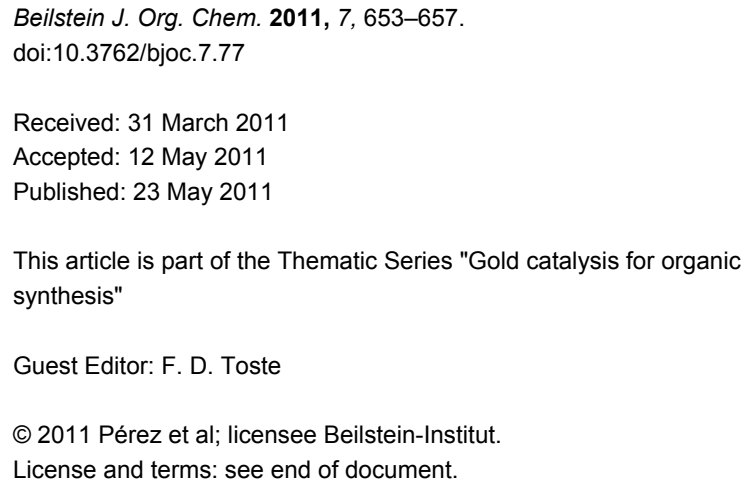

\begin{abstract}
The complexes IPrMCl (IPr = 1,3-bis(diisopropylphenyl)imidazol-2-ylidene, $\mathrm{M}=\mathrm{Cu}, \mathbf{1 a} ; \mathrm{M}=\mathrm{Au}, \mathbf{1 b}$ ), in the presence of one equiv of $\mathrm{NaBAr}_{4}\left(\mathrm{Ar}^{\prime}=3,5\right.$-bis(trifluoromethyl)phenyl), catalyze the transfer of carbene groups: $\mathrm{C}(\mathrm{R}) \mathrm{CO}_{2} \mathrm{Et}(\mathrm{R}=\mathrm{H}, \mathrm{Me})$ from $\mathrm{N}_{2} \mathrm{C}(\mathrm{R}) \mathrm{CO}_{2} \mathrm{Et}$ to afford products that depend on the nature of the metal center. The copper-based catalyst yields exclusively a cycloheptatriene derivative from the Buchner reaction, whereas the gold analog affords a mixture of products derived either from the formal insertion of the carbene unit into the aromatic $\mathrm{C}-\mathrm{H}$ bond or from its addition to a double bond. In addition, no byproducts derived from carbene coupling were observed.
\end{abstract}

\section{Introduction}

At the end of the nineteenth century, Buchner discovered [1] the thermal and photochemical route for the functionalization of benzene using diazo compounds to provide a carbene moiety. The first step of this transformation consists of the addition of such a unit to the aromatic double bond to give a norcaradiene intermediate that spontaneously undergoes ring opening to afford the more stable cycloheptatriene product (Scheme 1) [2]. Nearly one century later, Teyssié and co-workers discovered the potential of dirhodium tetraacetate and related $\mathrm{Rh}_{2}(\mathrm{~L}-\mathrm{L})_{4}$ compounds as catalysts for the decomposition of diazo compounds and subsequent transfer of the carbene moiety to several satu- rated and unsaturated substrates, including aromatics [3]. Thus, the reaction of ethyl diazoacetate (EDA) with benzene in the presence of such catalysts at room temperature exclusively affords the cycloheptatriene product in quantitative yields. The reaction, always referred to the intermolecular version, was later observed with other metal-based catalysts [4-6].

The above transformation with rhodium-based catalysts $[7,8]$ has also been investigated with naphthalene as a substrate. In this case, Teyssié and co-workers showed that it could be converted, using $t$-butyl diazoacetate, into norcaradiene type 


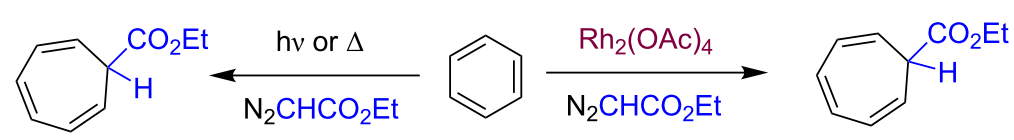

(a)

(b)

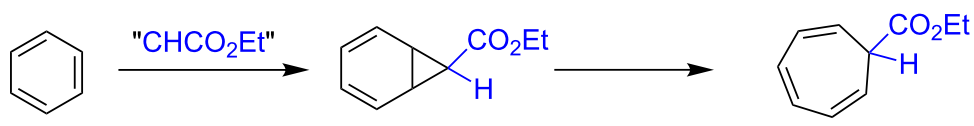

(c)

Scheme 1: (a) The Buchner reaction of benzene and ethyl diazoacetate and (b) the Rh-catalyzed version. (c) Both pathways involve the formation of norcaradiene intermediates.

derivatives, formed by the cyclopropanation of one of the double bonds of the naphthalene ring. Later, Müller and co-workers [9] showed the effect of a series of $\mathrm{Rh}_{2}(\mathrm{~L}-\mathrm{L})_{4}$ in the same transformation but with ethyl diazoacetate as the carbene source. A mixture of the products (2a-d) arising from cyclopropanation, ring opening and the formal insertion of $\mathrm{CHCO}_{2} \mathrm{Et}$ into the aromatic $\mathrm{C}-\mathrm{H}$ bonds were observed, with $\mathbf{2 a}$ being by far the major product (Scheme 2).

In the course of our research, focussed on the development of group 11 metal-based catalysts for carbene transfer reactions from diazo compounds [10], we found that the gold complex IPrAuCl (1b) (IPr = 1,3-bis(diisopropylphenyl)imidazol-2ylidene) in the presence of one equiv of $\mathrm{NaBAr}_{4}{ }_{4}\left(\mathrm{Ar}^{\prime}=3,5-\right.$ bis(trifluoromethyl)phenyl) induced the functionalization of benzene with ethyl diazoacetate to give a mixture of a cycloheptatriene and ethyl 2-phenylacetate [11], the latter being the result of the formal insertion of the $\mathrm{CHCO}_{2} \mathrm{Et}$ group into the
$\mathrm{C}-\mathrm{H}$ bond of benzene as well as the major product (Scheme 3). In this contribution, we report the results obtained from the analogous transformation using naphthalene as the substrate, with copper- and gold-based catalysts, not previously described for the functionalization of such fused arenes.

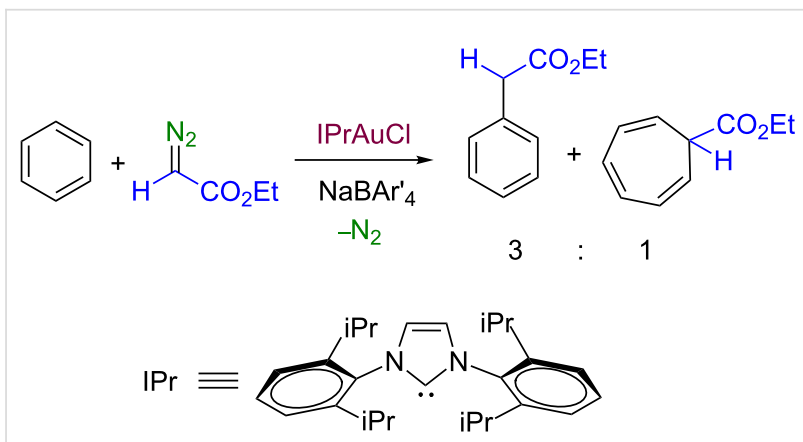

Scheme 3: The gold-catalyzed reaction of benzene and EDA.

(a)
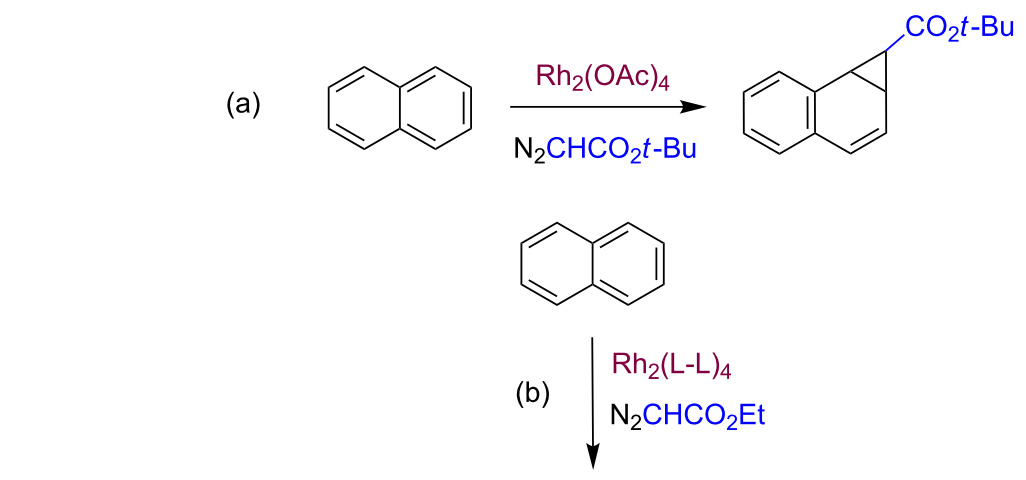<smiles>CCOC(=O)C1C2C=Cc3ccccc3C21</smiles>

$2 a$<smiles>CCOC(=O)Cc1cccc2c1=[C+]C=CC=2</smiles>

2b<smiles>CCOC(=O)c1ccc2ccccc2c1</smiles>

2c<smiles>CCOC(=O)C1C=Cc2ccccc2C=C1</smiles>

2d

Scheme 2: The Buchner reaction applied to naphthalene. (a) Teyssié's system. (b) Müller's system. 


\section{Results and Discussion}

\section{Reaction of naphthalene and diazoacetates catalyzed by IPrMCI (M = Cu, Au)}

When dichloroethane solutions of naphthalene were treated with ethyl diazoacetate in the presence of catalytic amounts (5\%) of a 1:1 mixture of $\operatorname{IPrMCl}(\mathrm{M}=\mathrm{Cu}, \mathbf{1} \mathbf{a} ; \mathrm{M}=\mathrm{Au}, \mathbf{1 b})$ and $\mathrm{NaBAr}_{4}{ }_{4}$, the diazo compound was consumed after $24 \mathrm{~h}$ at $60{ }^{\circ} \mathrm{C}$ (no significant reaction was observed at room temperature or at $40{ }^{\circ} \mathrm{C}$ ). NMR analysis of the crude reaction product revealed that when 1a was used as the catalyst, only one compound was formed, identified as ethyl 1a,7b-dihydro-1H-cyclopropa[a]naphthalene-1-carboxylate (2a), i.e., the product derived from the direct cyclopropanation of the naphthalene $\mathrm{C}-\mathrm{C}$ double bond (Scheme 4a). By contrast, the use of the gold catalyst $\mathrm{IPrAuCl}(\mathbf{1 b})$ under the same reaction conditions gave a mixture of three compounds, in ca. 65:20:15 ratio, that have been identified as 2a, ethyl 2-(naphthalen-1-yl)acetate (2b) and ethyl 2-(naphthalen-2-yl)acetate (2c). Compounds $\mathbf{2 b}$ and $\mathbf{2 c}$, respectively, are derived from the formal insertion of the carbene group into a $\mathrm{C}-\mathrm{H}$ bond of naphthalene (Scheme $4 \mathrm{~b}$ ).
The selectivity observed is similar to that reported by Müller's group with $\left[\mathrm{Rh}_{2}\left(\mathrm{O}_{2} \mathrm{CC}_{3} \mathrm{~F}_{7}\right)_{4}\right]$ (60:22:18) [8]. However, in our case the yield of products (EDA-based) was quantitative: products derived from dimerization of the diazo compound, i.e., diethyl fumarate and maleate, were not detected. The absence of the fused cycloheptatriene $\mathbf{2 d}$ in our system is also noteworthy. Substituted naphthalenes with $\mathrm{OMe}$ or $\mathrm{Cl}$ substituents at the beta position were also employed as substrates, however, the yields of the desired products were nearly negligible. The former seemed to induce the insertion into the Me groups, whereas in the latter case the aromatic reagent seemed deactivated.

We have expanded this reaction to ethyl 2-diazopropionate as the diazo component. Following a similar protocol, naphthalene was reacted in dichloroethane with ethyl 2-diazopropionate in the presence of a 1:1 mixture of $\mathbf{1 a}, \mathbf{b}$ and $\mathrm{NaBAr}_{4}(5 \%$ with respect to the diazo compound). Similarly to the previous results, the fused norcaradiene 3a (Scheme 5) was exclusively and quantitatively formed using the copper catalyst 1a, whilst

(a)

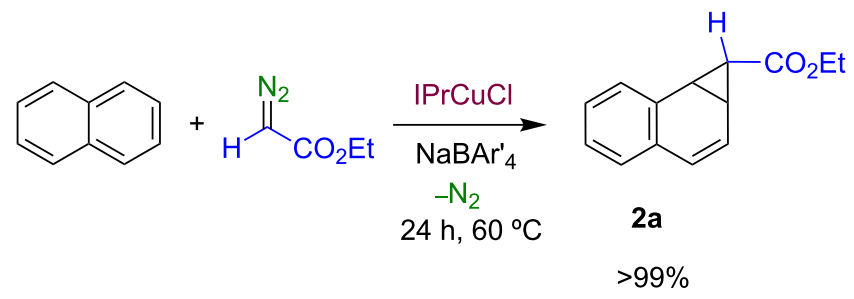

(b)
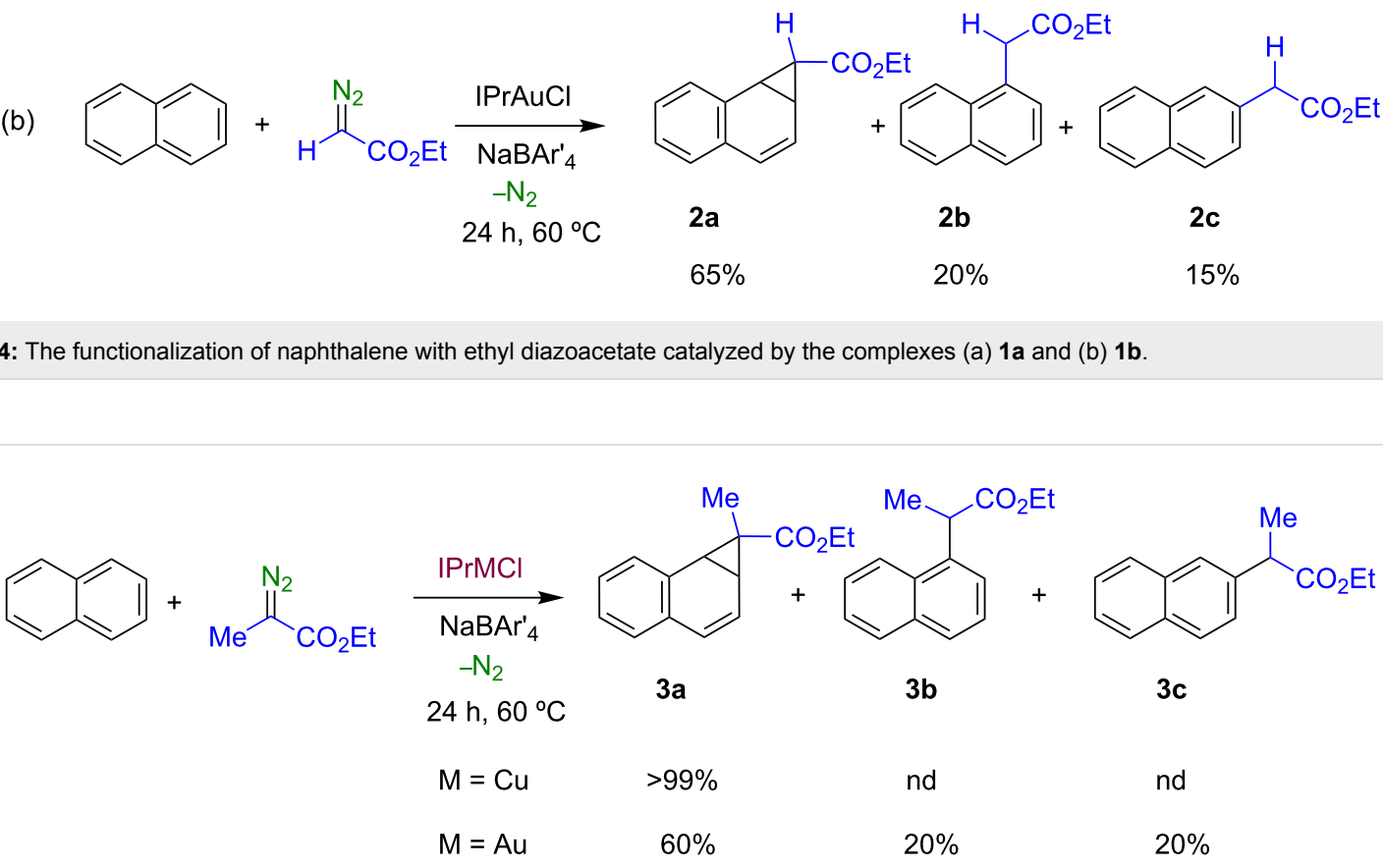
the use of $\mathbf{1 b}$ afforded a mixture of three products in a 60:20:20 ratio. The major product was identified as the $\mathbf{3 a}$ and the minor products have been characterized as the insertion products of the carbene $\mathrm{C}(\mathrm{Me}) \mathrm{CO}_{2} \mathrm{Et}$ into the $\alpha$ - and $\beta-\mathrm{C}-\mathrm{H}$ bonds of naphthalene, $\mathbf{3 b}$ and $\mathbf{3 c}$, respectively. When other diazo reagents such as $\mathrm{Me}_{3} \mathrm{SiC}\left(\mathrm{N}_{2}\right) \mathrm{CO}_{2}$ Et or $\mathrm{PhC}\left(\mathrm{N}_{2}\right) \mathrm{CO}_{2}$ Et were employed, intractable mixtures of compounds, probably due to multiple insertions, were observed by NMR.

It is also worth mentioning that the above transformations do not compete with the formation of byproducts derived from the catalytic dimerization of the diazo reagents, a common drawback in this methodology [2]. Despite of adding all the diazo compound in one portion at the beginning of the reaction, the final reaction mixture only showed resonances due to the aforementioned insertion and addition products. This is at variance with other reported systems that required the use of slow addition devices to diminish the formation of such byproducts.

\section{Conclusion}

The complexes IPrMCl $(\mathrm{M}=\mathrm{Cu}, \mathrm{Au})$ catalyze the transfer of carbene groups $\mathrm{C}(\mathrm{R}) \mathrm{CO}_{2} \mathrm{Et}(\mathrm{R}=\mathrm{H}, \mathrm{Me})$ to naphthalene, in the presence of $\mathrm{NaBAr}_{4}$ as halide scavenger, to give mixtures of products via carbene insertion into a $\mathrm{C}-\mathrm{H}$ bond or by addition to a double bond. In the case of copper, norcaradiene type compounds are formed quantitatively. The use of the gold analogue also induces the formation of such fused cyclopropanes in addition to the products derived from the formal insertion of the carbene units into the $\mathrm{C}-\mathrm{H}$ bonds of naphthalene. The system is completely chemoselective with regards to arene functionalization (with no diazo compound dimerization being observed).

\section{Experimental}

All reactions and manipulations were carried out under a nitrogen atmosphere. Organic solvents were dried, distilled, and degassed before use. The reagents were purchased from Sigma Aldrich. Complexes IPrMCl $(\mathrm{M}=\mathrm{Cu}, \mathbf{1 a} ; \mathrm{M}=\mathrm{Au}, \mathbf{1 b})$, $\mathrm{NaBAr}_{4}$ and ethyl 2-diazopropionate were prepared by literature procedures [12-16]. ${ }^{1} \mathrm{H}$ and ${ }^{13} \mathrm{C}$ NMR spectra were recorded on a Varian Mercury 400 spectrometer in $\mathrm{CDCl}_{3}$ as solvent, with chemical shifts $(\delta)$ referenced to internal standards.

\section{General catalytic experiment}

Complex 1 ( $0.025 \mathrm{mmol})$ was dissolved in dichloroethane $(5 \mathrm{~mL})$ and one equiv of $\mathrm{NaBAr}_{4}$ added to the solution, which was then added to a solution of naphthalene $(8.6 \mathrm{mmol}, 10 \mathrm{~mL})$ and heated at $60{ }^{\circ} \mathrm{C}$ in dichloroethane $(20 \mathrm{~mL})$. After stirring for

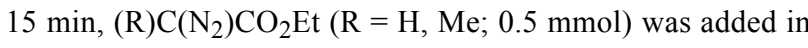
one portion, and the mixture stirred for $24 \mathrm{~h}$. Removal of volatiles followed by silica gel column chromatography $(1: 1$
$\mathrm{Et}_{2} \mathrm{O}$ :petroleum ether) gave a mixture of products. The products $\mathbf{2 a}, \mathbf{3 b}$ and $\mathbf{3 c}$ were identified by comparison with literature data [17-19], and $\mathbf{2 b}$ and $\mathbf{2 c}$ were compared authentic samples obtained from commercial sources.

Spectroscopic data for 3a: ${ }^{1} \mathrm{H}$ NMR $\left(400 \mathrm{MHz}, \mathrm{CDCl}_{3}\right) \delta$ 7.41-6.94 (m, 4H), $6.59(\mathrm{~d}, 1 \mathrm{H}), 6.06(\mathrm{dd}, 1 \mathrm{H}), 4.23(\mathrm{~m}, 2 \mathrm{H})$, $3.14(\mathrm{~d}, J=8.7 \mathrm{~Hz}, 1 \mathrm{H}), 2.72(\mathrm{dd}, J=8.8 \mathrm{~Hz}, 1 \mathrm{H}), 1.26(\mathrm{~s}, 3 \mathrm{H})$, $1.29(\mathrm{~m}, 3 \mathrm{H}) ;{ }^{13} \mathrm{C} \mathrm{NMR}\left(101 \mathrm{MHz}, \mathrm{CDCl}_{3}\right) \delta 169.0\left(\mathrm{CO}_{2} \mathrm{Et}\right)$, $146.4,134.5,133.4,129.6,128.5,127.7,126.6,125.5$ (aromatic), $63.1\left(\mathrm{COCH}_{2} \mathrm{CH}_{3}\right), 39.6,33.3,31.2$ (cyclopropyl), $19.52\left(\mathrm{CH}_{3}\right), 11.8\left(\mathrm{COCH}_{2} \mathrm{CH}_{3}\right)$; MS m/z (\%): 228 (70), 199 (30), 182 (100).

\section{Acknowledgements}

We wish to thank DGI (CTQ2008-00042BQU and Consolider Ingenio 2010, Grant CSD2006-0003) and Junta de Andalucía (P07-FQM-02870) for funding.

\section{References}

1. Buchner, E.; Curtius, T. Ber. Dtsch. Chem. Ges. 1885, 18, 2377-2379. doi:10.1002/cber.188501802119

2. Doyle, M. P.; McKervey, M. A.; Ye, T. Modern Catalytic Methods for Organic Synthesis with Diazo Compounds; John Wiley \& Sons: New York, 1998.

3. Anciaux, A. J.; Demonceau, A.; Noels, A. F.; Hubert, A. J.; Warin, R.; Teyssié, P. J. Org. Chem. 1981, 46, 873-876. doi:10.1021/jo00318a010

4. Morilla, M. E.; Díaz-Requejo, M. M.; Belderraín, T. R.; Nicasio, M. C.; Trofimenko, S.; Pérez, P. J. Organometallics 2004, 23, 293-295. doi:10.1021/om034156u

5. Lovely, C. J.; Browning, R. G.; Badarinarayana, V.; Dias, H. V. R. Tetrahedron Lett. 2005, 46, 2453-2455. doi:10.1016/j.tetlet.2005.02.052

6. Mbuvi, H. M.; Woo, L. K. J. Porphyrins Phthalocyanines 2009, 13, 136-152. doi:10.1142/S1088424609000036

7. Buchner, E.; Hediger, S. Ber. Dtsch. Chem. Ges. 1903, 36, 3502-3509. doi:10.1002/cber.190303603138

Buchner also discovered this transformation by heating of naphthalene and ethyl diazoacetate at $140{ }^{\circ} \mathrm{C}$.

8. Anciaux, A. J.; Demonceau, A.; Hubert, A. J.; Noels, A. F.; Petiniot, N.; Teyssié, P. H. J. Chem. Soc., Chem. Commun. 1980, 765-766. doi:10.1039/C39800000765

9. Müller, P.; Toujas, J.-L.; Bernardinelli, G. Helv. Chim. Acta 2000, 83, 1525-1534.

doi:10.1002/1522-2675(20000705)83:7<1525::AID-HLCA1525>3.0.CO ;2-1

10. Díaz-Requejo, M. M.; Pérez, P. J. Chem. Rev. 2008, 108, 3379-3394. doi:10.1021/cr078364y

11. Fructos, M. R.; Belderrain, T. R.; de Frémont, P.; Scott, N. M.; Nolan, S. P.; Díaz-Requejo, M. M.; Pérez, P. J. Angew. Chem., Int. Ed. 2005, 44, 5284-5288. doi:10.1002/anie.200501056

12. Jurkauskas, V.; Sadighi, J. P.; Buchwald, S. L. Org. Lett. 2003, 14, 2417-2420. doi:10.1021/ol034560p

13. de Frémont, P.; Scott, N. M.; Stevens, E. D.; Nolan, S. P. Organometallics 2005, 24, 2411-2418. doi:10.1021/om050111c 
14. Brookhart, M.; Grant, B.; Volpe, A. F., Jr. Organometallics 1992, 11, 3920-3922. doi:10.1021/om00059a071

15. Iwamoto, H.; Sonoda, T.; Kobayashi, H. Tetrahedron Lett. 1983, 24 , 4703-4706. doi:10.1016/S0040-4039(00)86232-2

16. Bachmann, S.; Fielenbach, D.; Jørgensen, K. A. Org. Biomol. Chem. 2004, 2, 3044-3049. doi:10.1039/b412053a

17. Huisgen, R.; Juppe, G. Chem. Ber. 1961, 94, 2332-2349. doi:10.1002/cber.19610940859

18. Fleming, F. F.; Liu, W. Eur. J. Org. Chem. 2009, 699-708. doi:10.1002/ejoc.200801053

19. Hou, J.; Zhou, H.; Zhou, Z.; Chen, L.; Ou, Q. Anal. Lett. 1996, 29 2755-2760.

\section{License and Terms}

This is an Open Access article under the terms of the Creative Commons Attribution License

(http://creativecommons.org/licenses/by/2.0), which permits unrestricted use, distribution, and reproduction in any medium, provided the original work is properly cited.

The license is subject to the Beilstein Journal of Organic Chemistry terms and conditions:

(http://www.beilstein-journals.org/bjoc)

The definitive version of this article is the electronic one which can be found at: doi:10.3762/bjoc.7.77 